\title{
Nanomechanical Response of Pulsed Tungsten Inert Gas Welded Titanium Alloy by Nanoindentation and Atomic Force Microscopy
}

\author{
Muhammad Hassaan, Massab Junaid, Tauheed Shahbaz, Muhammad llyas, Fahd Nawaz Khan, and Julfikar Haider (D)
}

Submitted: 19 July 2020 / Revised: 9 October 2020 / Accepted: 5 December 2020 / Published online: 8 January 2021

\begin{abstract}
Nanohardness and Effective Elastic Moduli were measured for pulsed-Gas Tungsten Arc Welded Ti-5Al2.5Sn alloy using autogenous mode through nanoindentation and atomic force microscopy. Experiments were conducted using a Berkovich tip on nanoindentor with Berkovich tip and elliptical pile ups were measured using an Atomic Force Microscope. Nanohardness and effective elastic moduli were calculated in the base metal, heat affected zone and fusion zone of the weldments using different approaches namely Oliver-Pharr method, AFM analysis and work of indentation. A significant difference was observed in the nanomechanical response using these approaches which was attributed to the pile up morphology of the nano indents. The presence of residual stress in the weldments also significantly influenced the nanohardness profile across the weld joint. The present research suggested that the work of indentation is most suitable for assessment of nanomechanical properties of Ti-5Al-2.5Sn alloy weldments among the three techniques studied in this investigation.
\end{abstract}

Keywords atomic force microscope, gas tungsten arc welding (GTAW), nanoindentation, nanomechanical properties, nanohardness, titanium alloy, work of Indentation

\section{Introduction}

In various aerospace applications, high performance light weight alloys experience different cycles of loading conditions. Titanium alloys are extensively used in critical aerospace applications due to their attractive properties such as high strength to weight ratio, high toughness and specific strength, and good corrosion resistance. These properties of titanium alloys have led to their application in various critical applications in aerospace, automotive, petrochemical and biomedical industries. As compared to steel, they are significantly lighter but exhibit nearly the same strength levels (Ref 1). Titanium alloys are also biocompatible and are mostly used in implants and for different joints' replacement surgeries in the human body (Ref 2). The excessive use of titanium in designing and manufacturing demands a high strength joining mechanisms providing sufficient metallurgical and mechanical properties to bear the design loads.

Muhammad Hassaan, Massab Junaid, and Muhammad Ilyas, Faculty of Mechanical Engineering, Ghulam Ishaq Khan Institute of Engineering Sciences and Technology, Topi 23640, Pakistan; Tauheed Shahbaz and Fahd Nawaz Khan, Faculty of Materials and Chemical Engineering, Department of Materials Science, Ghulam Ishaq Khan Institute of Engineering Sciences and Technology, Topi 23640, Pakistan; and Julfikar Haider, Advanced Materials and Surface Engineering (AMSE) Research Centre, Manchester Metropolitan University, Chester Street, Manchester M1 5GD, UK. Contact e-mails: massab@giki.edu.pk and j.haider@mmu.ac.uk.
From a structural standpoint, welded joints are critical from the aspect of failure. They are alternative to mechanical fasteners such as rivets which were conventionally used. Different welding processes have been used to join titanium alloys such as GTAW, laser, electron beam, friction stir welding processes (Ref 3 ). The weld zone strength is representative of its usability and quality (Ref 4). Assessing mechanical properties of the weldments such as hardness, elastic modulus etc. are essential to ensure its strength and integrity in service.

Initially, hardness was measured using different approaches. Brinell hardness having ball diameter in order of millimeters $(10 \mathrm{~mm})$ was used in 1900s (Ref 5). Rockwell developed a machine to measure hardness using ball diameter of $3.17 \mathrm{~mm}$ or cone of $0.2 \mathrm{~mm}$ tip. Similarly, Vickers and Knoop hardness tests were developed. But it was difficuilt to indent at micro scale due to difficulty of all the edges touching the material at such a small scale. Hence, berkoich tip was developed which had triangular pyramid (Ref 6). Mott (1957) and Buckle (1959) coined the field of microhardness (Ref 7$)$. Due to a small tip diameter of the indenter deformations at the grain boundaries and second phase particles could be studied (Ref 8). Bulychev et al. (1975) used the unloading curve of the Load-depth curve to measure area of contact and became building block for the present measurement techniques at nano level (Ref 9).

Value of hardness is important in numerous studies. Depending on the applications, either high or low hardness is advantageous. For example, if the hardness of alloys used in dental implants is more than enamel, it may wear the enamel of the teeth (Ref 10$)$. Hence, the determination of hardness is very crucial for many applications. According to Tabor et al. (Ref 11), the indentation hardness is referred as the measure of the yield stress of the solid as given by the deformation and work hardening produced by the indentation process. Plastic deformation had been the point of interest for many researchers since it significantly influences the hardness of metallic alloys. The theory of slip-line fields, was coined, to explain the plastic working of the metals (Ref 11). Et al. studied anisotropic plastic 
deformation of metals under triaxial loading (Ref 12). Et al. quantified plastic flow during hot working of Ti-7Al with an equiaxed- $\alpha$ microstructure (Ref 13)..

Assessment of the properties of materials at nano level is required for observing the physical phenomenon involved in strengthening of the weldments. Microhardness does not provide such resolution to observe the changes at the individual grain. Therefore, the use of nanoindentation makes it possible to study the hardness of individual grain. Single grain can be indented multiple times to obtain averaged hardness of grain. Therefore, it is necessary in observing the localized strengthening mechanism in the weldments at grain level (Ref 14). Oliver and Pharr (Ref 15) introduced a method for the measurement of hardness and elastic modulus using nanoindentation. However, this method is valid only for the materials that sink in, it does not work for the materials that pile up during indentation (Ref 16). Kese et al. (Ref 17) used the images from atomic force microscope (AFM) of the residual indents to include the area of pile up and add it to the area calculated by the Oliver and Pharr method. Nevertheless, the problem with AFM imaging is that elastic recovery takes place between indentation and imaging due to which the measured values are appeared to be less than the actual values. Tuck et al. (Ref 18) used work of indentation approach to calculate nanoproperties of thick TiN coating on a tungsten carbidecobalt substrate used for the case of bulk hard materials.

Instrumented indentation is being used to characterize the properties of many materials such as thin films on substrates, welded joints, biomaterials (dental crowns etc.) and many more. Previous methodologies that characterize the properties of welded joints are destructive. In addition to this, nanoindentation also has high resolution and can apply low enough forces to give penetration depths less than the required, i.e., $10 \%$ or so of the film thickness, so as to avoid influence on the hardness due to the presence of substrate. Simple sample preparation and eases of operation of nano indenters makes it a suitable choice for hardness measurement (Ref 19).

Fusion/Weld zone, besides HAZ and BM, is an equally important region for weldment's usability and quality (Ref 4). Hence, the present study is conducted to analyze the nanomechanical response of the three zones present in the weld nugget, i.e., FZ, HAZ and BM. Oliver-Pharr method, AFM analysis and work of indentation are three methods adopted to assess the Nano hardness using nanoindenter and atomic force microscope. The focus is on the comparison of these methodologies and the involved underlying principles with vicker hardness testing to determine their applicability in assessment of strengthening of Ti-5Al-2.5Sn weldments obtained using autogenous pulsed-GTAW process. This is a basic step to develop further understanding about the structure-property relations in titanium alloy weldments in terms of its grain boundaries, free surfaces and slip planes etc.

\section{Materials, Methods and Mathematical Formu- lations}

\subsection{Material and Welding Conditions}

P-GTAW in autogenous mode was performed in bead on plate $(\mathrm{BoP})$ configuration on a $1.6 \mathrm{~mm}$ thin sheet of Ti-5Al$2.5 \mathrm{Sn}$ alloy with a size of $40 \mathrm{~mm} \times 4 \mathrm{~mm}$. The chemical composition (wt.\%) of the alloy was: $5.34 \mathrm{Al}, 2.56 \mathrm{Sn}, 0.27 \mathrm{Fe}$, $0.17 \mathrm{O}, 0.02 \mathrm{~V}, 0.03 \mathrm{Si}, 0.01 \mathrm{C}, 0.01 \mathrm{~N}$ and balanced Ti.

The optimized welding parameters and conditions to achieve full penetration BoP weldments for Pulsed-GTAW in autogenous mode are presented in Table 1. Feeler (leaf) gauges were used to set up the distance between workpiece and electrode prior to welding in order to measure the arc length. To protect titanium surface from atmospheric reaction, argon gas was used for shielding and the weld beads having complete penetration were selected for further study. Gao et al. (2013) (Ref 20) stated that edge preparation and filler metals are not required for the welding of thin titanium alloy sheets. Leyens and Peters (2003) (Ref 1) reported that joint preparation before welding and use of filler material is not required for sheets having thickness less than $3 \mathrm{~mm}$. In the present study $1.6 \mathrm{~mm}$ thick sheets of Ti-5Al-2.5Sn were welded. Therefore, filler material was not used. Moreover, the formation of a v-groove is required in the case of thick sheets. Whereas the present study was conducted on thin Ti-5Al-2.4Sn sheets. Hence, edge preparation was not done for these sheets.

In general, direction of welding is maintained perpendicular to the base plate rolling direction for achieving better strength of the welded joints. However, in this case the welding was conducted along the rolling direction of the base plate. Base plate was annealed after rolling therefore, the grains were equiaxed (as shown later in the microstructure) and not elongated. Hence, the material's percentage elongation and yield strength were measured to be the same in both directions.

\subsection{Optical Microscopy}

In order to study the microstructure of welded section, metallographic samples were ground using water abrasive paper up to 4000 grit, followed by mechanical polishing, using $1 \mathrm{~mm}$ diamond suspension paste. Furthermore, these samples were etched first with Kroll solution $\left(6 \% \mathrm{HNO}_{3}\right.$ and $2 \% \mathrm{HF}$ by volume in distilled water), followed by etching with $2 \% \mathrm{HF}$. The samples were studied under Olympus BH2-UMA optical microscope (OM) using polarized light and sensitive tint filter.

\subsection{Nanoindentation}

These metallographic specimens were further used for testing in Nano indenter (iMicro from Nanomechanics, Inc.) with a Berkovich indenter tip. In iMicro nanoindenter a unique tip-calibration system is integrated into the software that allows for fast, accurate and automated tip calibration. Nanoindenter has a drift rate of $<0.05 \mathrm{~nm} / \mathrm{s}$ and a damping coefficient of $0.05 \mathrm{~N}-\mathrm{s} / \mathrm{m}$. A grid of $3 \times 3$ was placed at each weld zone viz. FZ, HAZ, BM. This grid is shown in Fig. 1 using a schematic diagram.

The maximum load was kept to approximately $550 \mathrm{mN}$ and depth was varied from approximately $2500 \mathrm{~nm}$ to $2800 \mathrm{~nm}$. The choice of load is dependent on a number of factors. For instance, surface oxidation may significantly overestimate the nanohardness of a bulk material (Ref 22). Mante et al. estimated the nanohardness of polycrystalline bulk titanium using various depth of indentations. They observed that there was a $34 \%$ increase in the nanohardness value when indentation was performed close to the surface $(<100 \mathrm{~nm})$. However, when the indentation was performed at a depth of $2000 \mathrm{~nm}$, values of hardness were close to the standard values (Ref 23).

Other research studies related to indention of bulk material were also investigated to choose a value of indentation load. 
Table 1 Optimized pulsed-GTAW (autogenous) parameters [21]

\begin{tabular}{|c|c|c|c|c|c|c|}
\hline \multicolumn{2}{|c|}{ Current } & \multicolumn{2}{|c|}{ Pulse width } & \multirow[b]{2}{*}{ Voltage } & \multirow[b]{2}{*}{ Welding speed } & \multirow[b]{2}{*}{ Arc Length } \\
\hline Primary & Background & High & Low & & & \\
\hline $32 \mathrm{~A}$ & $16 \mathrm{~A}$ & $8 \mathrm{~ms}$ & $4 \mathrm{~ms}$ & $10 \mathrm{~V}$ & $32.5 \mathrm{~mm} / \mathrm{min}$ & $4 \mathrm{~mm}$ \\
\hline
\end{tabular}

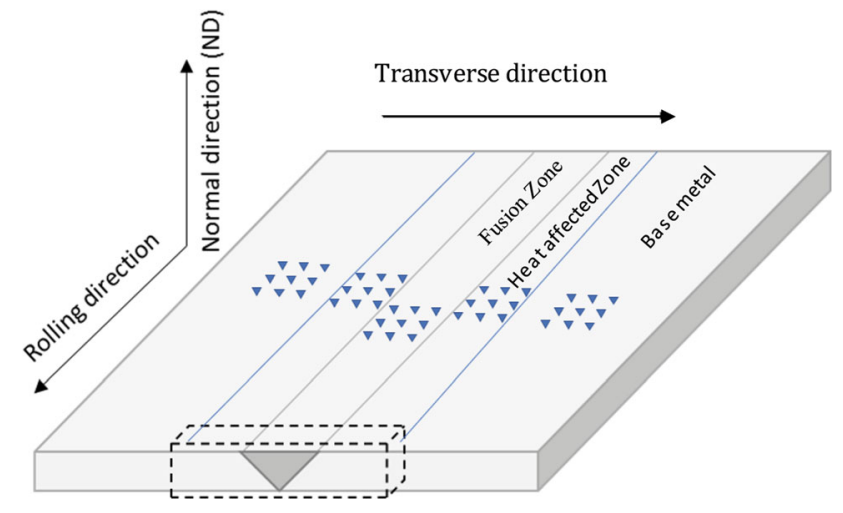

Fig. 1 Schematic diagram showing different zones in a weld and indents taken at these zones

Attar et al. investigated the hardness and elastic modulus of $\mathrm{Ti}$ and $\mathrm{TiB}$ composite materials produced by selective laser melting (SLM). They loaded both materials at $10 \mathrm{mN}$ and the resultant depth was $350 \mathrm{~nm}$ for Ti, whereas $260 \mathrm{~nm}$ for Ti-TiB composite (Ref 24). Jamleh et al. also studied nanoindentation by Berkovich indenter tip. They studied the effect of cyclic fatigue on nickel-titanium (NiTi) endodontonic instruments. They kept the maximum load of $100 \mathrm{mN}$ and got the resultant depth of $1300 \mathrm{~nm}$ (Ref 25). A review of all these studies suggests that for titanium alloys, a figure of approximately $2000 \mathrm{~nm}$ would be adequate for indentation measurements which would require a load in the range of $\sim 500 \mathrm{mN}$. During nanoindentation testing, the depth of penetration is continuously measured with the increasing load. This gives the loading and the unloading curves, which are then used to measure different properties using different models to calculate hardness, elastic modulus, residual stresses etc. of different specimen.

2.3.1 Oliver and Pharr Approach. OP (Oliver and Pharr) approach is the foundation of nanoindentation which equips with the formulation for measurement of different mechanical properties, i.e., hardness and elastic modulus as discussed by Oliver and Pharr. Reference 26 These Eqs. are given as follows:

$H=\frac{P_{\max }}{A_{c}}$

Where $A_{c}$ is given by:

$A_{c}=C_{1} h_{c}^{2}+C_{2} h_{c}+\ldots C_{8} h_{c}^{1 / 128}$

Here $C_{n}$ are the constants which are found by the curve fitting process (Ref 26).

It is a very reasonable approach to fix the indentation depth for all the experiments on Nanoindenter and then calculate the peak force required to acquire the peak depth. The level of residual stress can be evaluated using the difference in peak force (Ref 27). To incorporate the effect Berkovich tip deformation on the elastic modulus of the material at nano level, the effective elastic modulus is used (Ref 15). Oliver and Pharr approach defines the reduced or combined elastic modulus by considering the elastic deformation of both the specimen and the indenter.

It can be found from the unloading stiffness as:

$E_{\text {eff }}=\frac{S \sqrt{\pi}}{2 \beta \sqrt{A}}$

Where $\beta$ is a dimensionless parameter which accounts for the deviations in stiffness caused by lack of axial symmetry for pyramidal indenters or any other physical processes (Ref 26).

The choice of maximum penetration depth for a specific material has not been clearly mentioned in the literature. Usually it is chosen approximately $1500 \mathrm{~nm}$ for low alloyed and austenitic stainless steels (Ref 28), 200-250 nm for carbon steel SS400 (Ref 29), $600 \mathrm{~nm}$ for aerospace aluminum alloys (Ref 30) and $200 \mathrm{~nm}$ for Al-Mg and Al-Mg-Si alloys. Reference 31 There is no hard and fast rule to follow these guidelines, but the choice of maximum penetration depth also depends on the type of problem under study. For instance, in a material consisting of two phases, an indentation depth (h) of magnitude less than the characteristic length D of each phase microstructure will give information about the material property of a single phase. But if $h \gg D$, the indentation response will give access to average material properties of the material in a statistical sense. In the later case, even one indent will be enough for the test, but in the former case, more than one indent is needed to determine the phase properties of material (Ref 32). Larger penetration depth may also result in extreme pile up around the indenter tip which will result in overestimation of the hardness value. It should be noted that Oliver and Pharr method is based on no pile up ( $\operatorname{Ref} 17,33,34)$.

2.3.2 AFM Area Measurement Approach. This approach has been used by Beegan et al. and Saha and Nix (Ref 35,34 ) by taking the pile ups around the indent as circular arc. However, Kese et al. (Ref 17) considered the pile up around the indent to be in the form of a semi-ellipse. By considering the pile up to be in the form of semi-ellipse like the one shown in the Fig. 2, the pile ups can be calculated from the AFM images.

Edge $\mathrm{L}$ in the figure is the edge where the pile up is starting, whereas Edge $\mathrm{T}$ is the edge where the maximum height of the pile up occurs. A Berkovich indenter tip has a geometrically self-similar pyramidal shape with an included half angle of $65.27^{\circ}$. That is the reason that the tip produces the indent that is in the form of an equilateral triangle as shown by a schematic diagram in Fig. 3. Here $a$ is the length of the minor axis of the semi-ellipse, whereas $b$ is the length of the major axis of the semi-ellipse. 


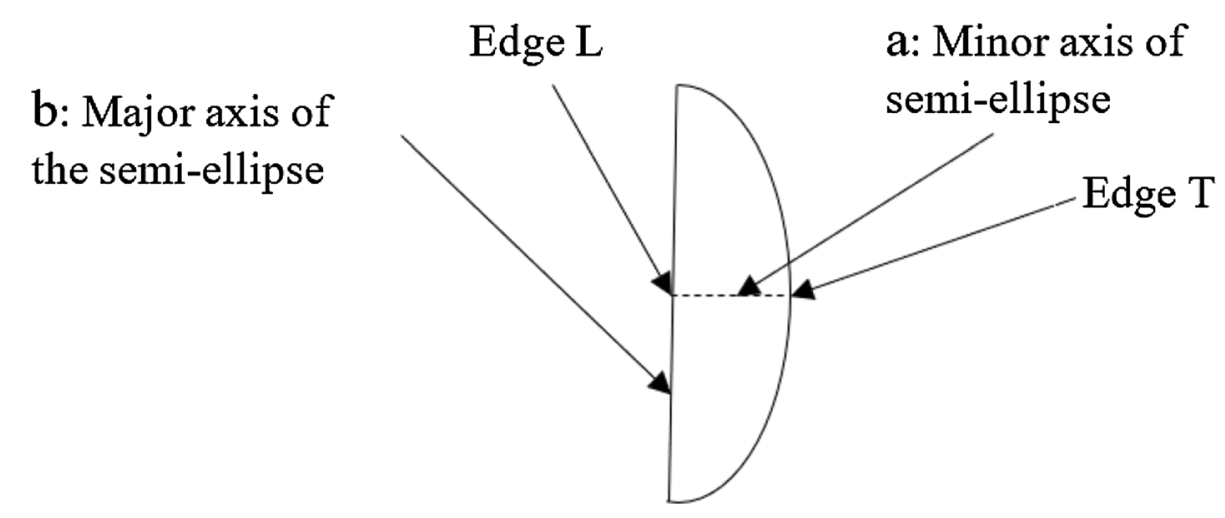

Fig. 2 Semi-ellipse (schematic diagram) showing the shape of pile up around indent

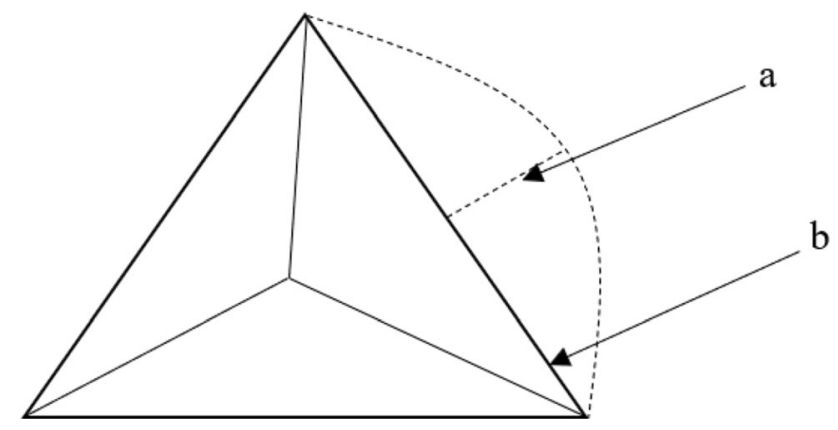

Fig. 3 Equilateral triangular indent formed by the indent of Berkovich tip

The area of an equilateral triangle is given by:

$$
A_{e q}=\frac{b^{2}}{4} \tan 60^{\circ}=0.433 b^{2}
$$

For a perfect Berkovich tip we have:

$$
\begin{gathered}
A_{c}=A_{e q} \\
24.56 h_{c}^{2}=0.433 b^{2} \\
b=7.531 h_{c}
\end{gathered}
$$

Where $A_{c}$ is the contact area for a perfect Berkovich tip without including the pile up. Using the above relation, we now have the value for the major axis of the semi-elliptical pile up. Now the area of the semi-ellipse is given by:

$$
\text { Area }=\frac{\pi a b}{4}
$$

As the value of minor axis of semi-ellipse $(a)$ for each of the pile ups is change therefore, we have:

$A_{p u}=\frac{\pi b}{4} \sum a_{i}=5.914 h_{c} \sum a_{i}$

Therefore, now the total area of the indent is the summation of the contact area calculated using area function of Oliver and Pharr method and the pile up area.

$A=A_{o p}+A_{p u}=A_{o p}+5.914 h_{c} \sum a_{i}$
Equation 5 is used by Kese et al. (Ref 17) to calculate the area that includes the area of the pile ups. This area is then used to calculate the nanohardness.

2.3.3 Total Work Approach. This approach of calculating hardness was introduced by Tuck et al. (Ref 18). In this approach, hardness is calculated using the work of indentation based on load-depth curve obtained through nanoindenter. Total work is measured using area under the loading curve. Whereas elastic work is measured using area under the unloading curve. According to Tuck et al., the work can be found as the area under the load-depth curve, i.e.

$W_{t}=\int_{0}^{h_{\max }} P d h$

$$
W_{t}=\int_{0}^{h_{\text {max }}} C h^{2} d h\left(P=C h^{2} \text { given by Kick's law }\right)
$$

$W_{t}=\frac{C h_{\max }^{3}}{3}=\frac{P_{\max } h_{\max }}{3}$

Now the hardness can be calculated using either the Berkovich or the Vickers indentation testing, but for both the generalized formula can be written as (in terms of depth of penetration):

$H=\frac{k P}{h^{2}}$

Where $\mathrm{k}=0.0378$ for Vickers four-sided pyramidal indenter

And $\mathrm{k}=0.0408$ for the three-sided Berkovich pyramidal indenter

Rearranging the above relation:

$$
P=\frac{H h^{2}}{k}
$$

Putting this value of $P$ and $H$ in Eq 7 and integrating:

$W_{t}=\int_{0}^{h_{\max }} \frac{H h^{2}}{k} d h=\frac{H h_{\max }^{3}}{3 k}=\frac{P_{\max } h_{\max }}{3}$

Also, from $\mathrm{Eq} 8, \mathrm{~h}$ is given as: 


$$
h=\sqrt{\frac{k P}{H}}
$$

Putting it in Eq 9 to get:

$H=\frac{k P_{\max }^{3}}{9 W_{t}^{2}}$

Hardness definition requires that above formulation must contain only the plastic work, so if we replace the total work by plastic work, we get hardness in terms of plastic work.

2.3.4 Plastic Work Approach. As discussed previously, if we replace the total work by plastic work in the formula for the hardness, we satisfy the hardness definition and get:

$H=\frac{k P_{\max }^{3}}{9 W_{p}^{2}}$

Plastic work can be calculated by subtracting the elastic work from the total work.

$$
W_{p}=W_{t}-W_{e}
$$

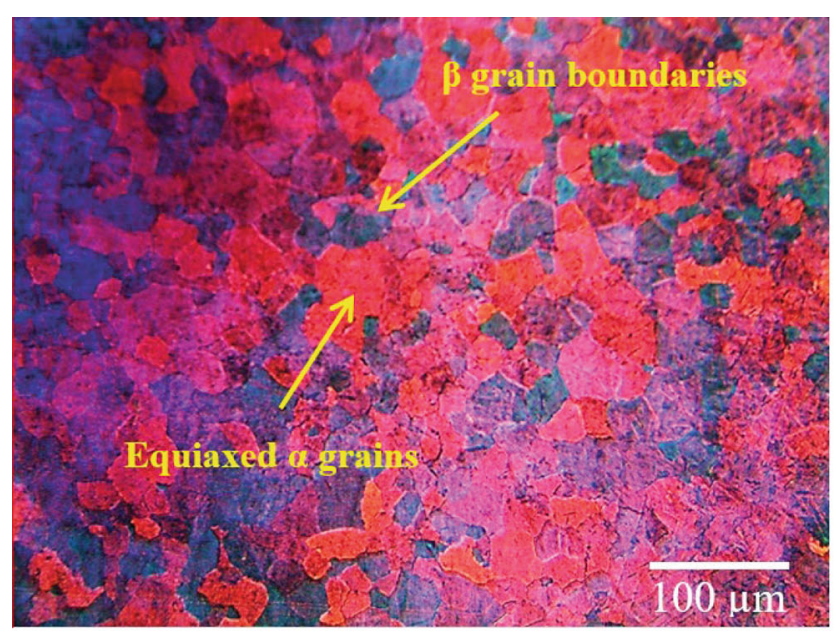

(a)
Here, the elastic work is calculated by using kick's law and integrating the unloading curve:

$$
W_{e}=\int_{h_{f}}^{h_{\max }} P d h=\frac{P_{\max } h_{\max }}{3}-\frac{P_{f} h_{f}}{3}
$$

The above method is used to calculate hardness value without taking into account the value of area. Therefore, it will not be affected by the pile ups (Ref 18).

\section{Results and Discussions}

Nanoindentation was carried out in an array of $3 \times 3$ indents placed in each of the three zones in the weldment viz. $\mathrm{BM}, \mathrm{FZ}$ and HAZ. These zones are different from the aspect of microstructure as shown in Fig. 4. The BM is comprised of equiaxed $\alpha$ grains in a $\beta$ matrix. Furthermore, moving toward the FZ in Fig. (4c) via the HAZ in Fig. (4b), a significant grain growth and formation of microstructure (acicular $\alpha$ and $\alpha$ ' martensite) was observed. Such a microstructure is suggestive

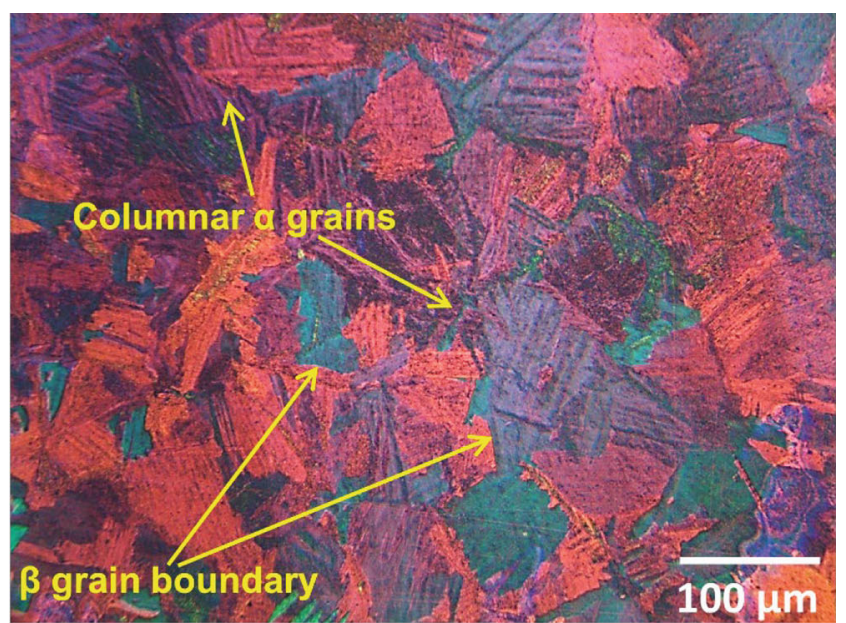

(b)

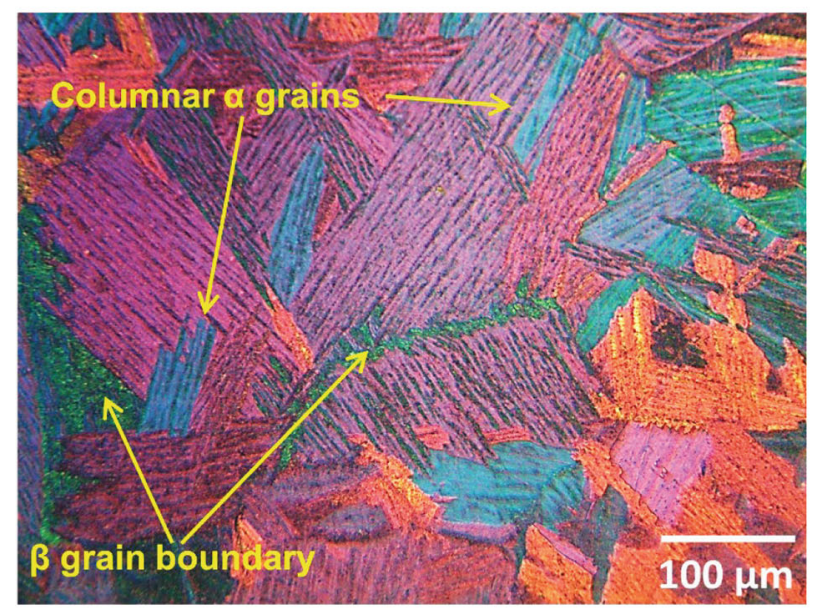

(c)

Fig. 4 Microstructures of different zones in the P-GTAW weldment in autogenous mode (a) Base metal, (b) HAZ and (c) FZ 


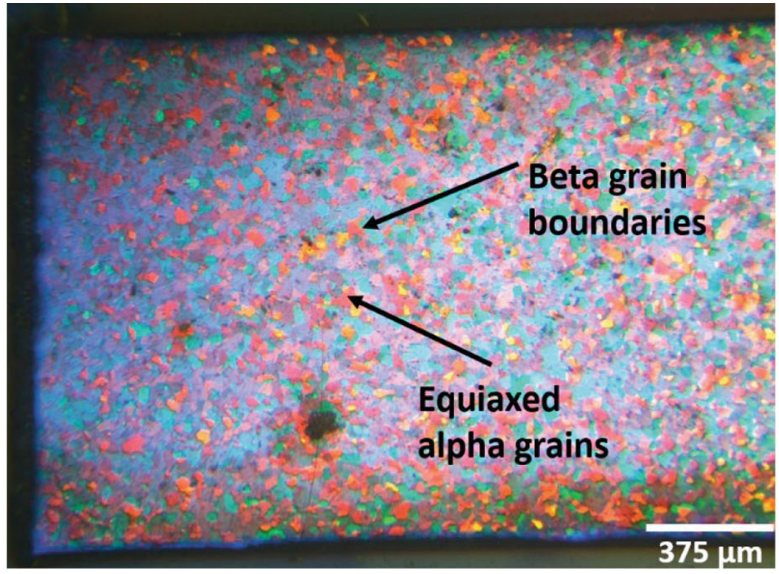

(a)

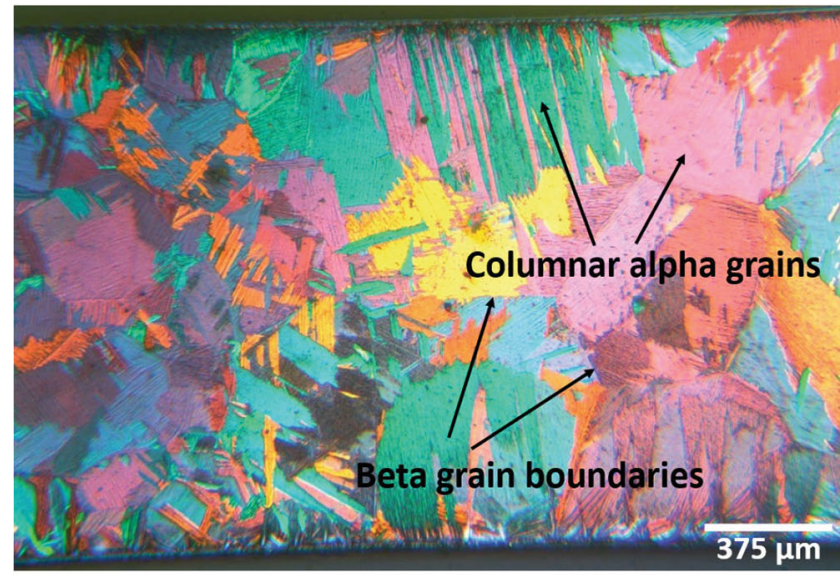

(c)

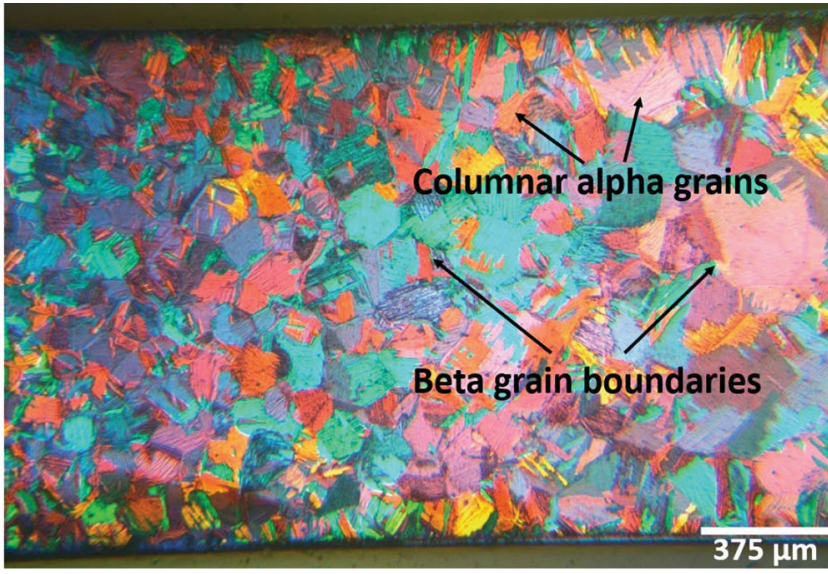

(b)

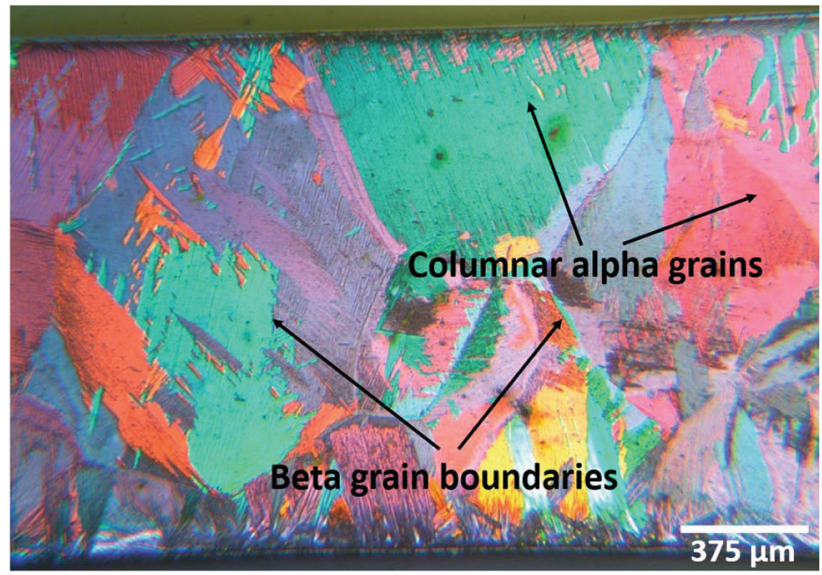

(d)

Fig. 5 Cross-sectional view of pulsed-GTAW (autogenous mode) weldment of Ti-5Al-2.5Sn alloy at $50 \times$ magnification for (a) BM, (b) HAZ, (c) FZ (Edge), (d) FZ (Middle)

of higher cooling rates experienced by the HAZ and FZ during the cooling cycle of the P-GTAW in autogenous mode (Ref 21). Cross sections of the three zones of the weldment are also shown in the Fig. (5).

During nanoindentation, the maximum load for each indent was held constant at $533 \mathrm{mN}$ and the corresponding maximum indentation depth was observed in the range of 2500 to $2800 \mathrm{~nm}$. The image of indent array is shown in Fig. 6 and the corresponding load-depth curves of nano indentation are shown in Fig. 7. Nanohardness for each zone was calculated using these load-depth curves by different approaches discussed earlier, i.e., Oliver and Pharr approach, AFM analysis and Work of Indentation.

During nanoindentation, the material around the indents was accumulated in the form of pile ups due to significant deformation. Atomic force microscopy (AFM) was used to observe these pile ups in three-dimensions as shown in Fig. 8. This AFM imaging also enables to measure the amount of accumulated pile up around the indents through which the deformation could be quantified.

In Fig. 9, the values of nanohardness for the base metal (BM) calculated using the approaches of Oliver and Pharr (OP method), AFM analysis (AFM method) and work of indentation (Total work and Plastic work) are shown. It can be observed that the value of nanohardness is dependent on the penetration depth. Furthermore, it can also be observed that the OP hardness has the highest value for all the nanoindents which is owing to the fact that OP method is not taking into account the area of pile ups due to which hardness is overestimated (Ref 18). In OP method, contact area was measured using the area function relating the area with the penetration depth according to $\mathrm{Eq} 2$. The constants in this equation are found by the curve fitting procedure in which the first constant in Eq 2 corresponds to a perfect tip whereas the other constants take into account the deviation of the tip from its original shape due to wear or inaccurate assembly (Ref 26). Consequently, in OP method, the hardness is overestimated owing to the omittance of area around the pileups.

To address this issue, Kese et al. (Ref 17) introduced the method of adding up the pile up area estimated from AFM imaging in the area function of the OP method. It can be further observed in Fig. 9 that the value of nanohardness is the least when the pile up area, measured through AFM analysis is taken into account. This is attributed to the elastic recovery leading to overestimation of the pile up areas as also shown by load-depth curves in Fig. 7. The value of nano hardness calculated from total and plastic work approach are very close to each other. As shown in Fig. 7, the material is elastically recovering during unloading stage and the slope of the unloading curve is very high due to which area under the curve is very small and hence 


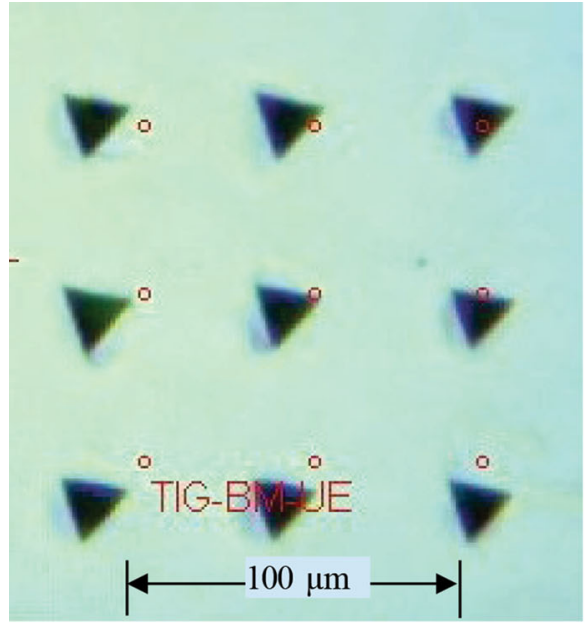

(a)

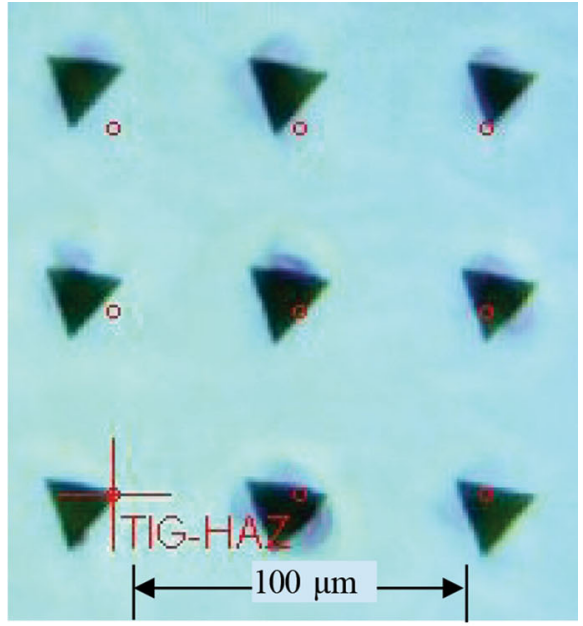

(b)

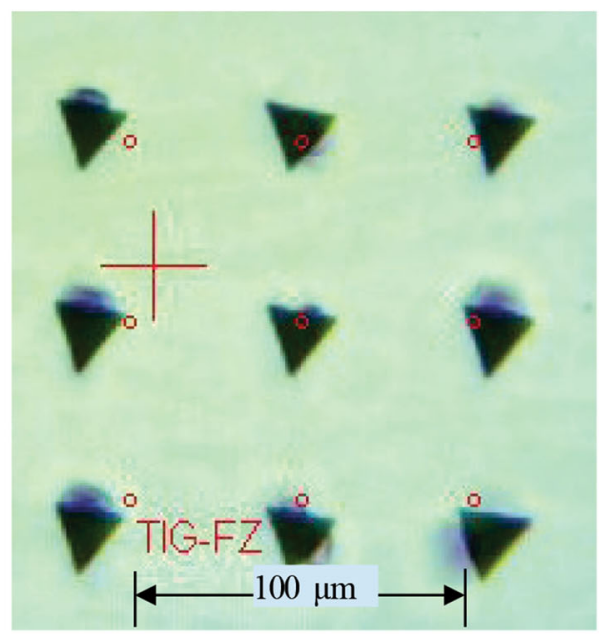

(c)

Fig. 6 Two-dimensional optical images with indentation marks generated on polished specimens of pulsed-GTAW welded (autogenous mode) Ti-5Al-2.5Sn alloy at $\sim 550 \mathrm{mN}$ showing indentations in each of (a) BM, (b) HAZ and (c) FZ

less elastic work is produced. Therefore, the pile ups were enhanced after unloading and could be observed through AFM (Fig. 8) for the region which had recovered elastically.

Similar trend of variation in nanohardness can be observed for HAZ and FZ in Fig. 10 and 11 respectively. The OP method overestimated, while the AFM analysis underestimated the values of nano hardness values in the BM, HAZ and FZ as compared to the corresponding micro hardness values. The value of nanohardness calculated through work of indentation approach lie in between the nanohardness calculated through OP method and AFM analysis and is significantly closer to the value of microhardness in a specific region. Nanohardness calculated using total work approach is $3.35 \mathrm{GPa}, 3.11 \mathrm{GPa}$, $3.06 \mathrm{GPa}$ and that using plastic work approach is $3.36 \mathrm{GPa}$, $3.12 \mathrm{GPa}$ and $3.09 \mathrm{GPa}$ for BM, HAZ and FZ, respectively. This similarity is owing to the fact that it is calculated directly using load-depth curves and is independent of the pile up area of indents. These values are given for comparison in Table 2. Effective elastic modulus calculated through the experimentation for all three regions is given in Fig. 12.

To further investigate, the pile behavior of nanoindents in different zones of the pulsed-GTAW weldments of Ti-5Al$2.5 \mathrm{Sn}$ alloy in autogenous mode, the normalized hardness
$\left(H / E_{r}\right)$ and the normalized pile up/sink in height $\left(h_{c} / h_{m}\right)$ were plotted. According to Biwa et al. and Hill et al. (Ref 36, 37), nanoindents for materials having low $H / E_{r}$ values (soft materials) show pile up when $h_{c} / h_{m}$ (contact depth to maximum depth ratio) approaches unity. Similarly, for hard materials having a high $H / E_{r}$ value show sink in behavior around the indents when $h_{c} / h_{m}$ approaches zero (Ref 38). $h_{c} / h_{m}$ calculated for BM comes out to be $0.945 \approx 1$ and $H / E$ to be in the range $0.01-0.037$, suggestive of pile up around the nanoindents. Figure 13, 14 and 15 show the values of normalized pile up/sink in height and normalized hardness for the BM, HAZ and FZ regions. It can be observed that the value of $\left(h_{c} / h_{m}\right)$ is in the range 0.937-0.947 for BM, HAZ and FZ which is close to unity and is suggestive of pile ups around the indents which can also be observed in Fig. 8. Hence, according to Biwa et al. and Hill et al. (Ref 36, 37), deformation is dominated by pile up for all the zones of the Ti-5Al-2.5Sn weldment. Among the three zones in the weldment, the highest value of $H / E$ in $\mathrm{FZ}$ is observed to be 0.03 which is $18 \%$ less than the corresponding highest value of $H / E$ in the HAZ region. This leads to an apparent softness in the FZ and may be attributed to the presence of tensile residual stresses which were 

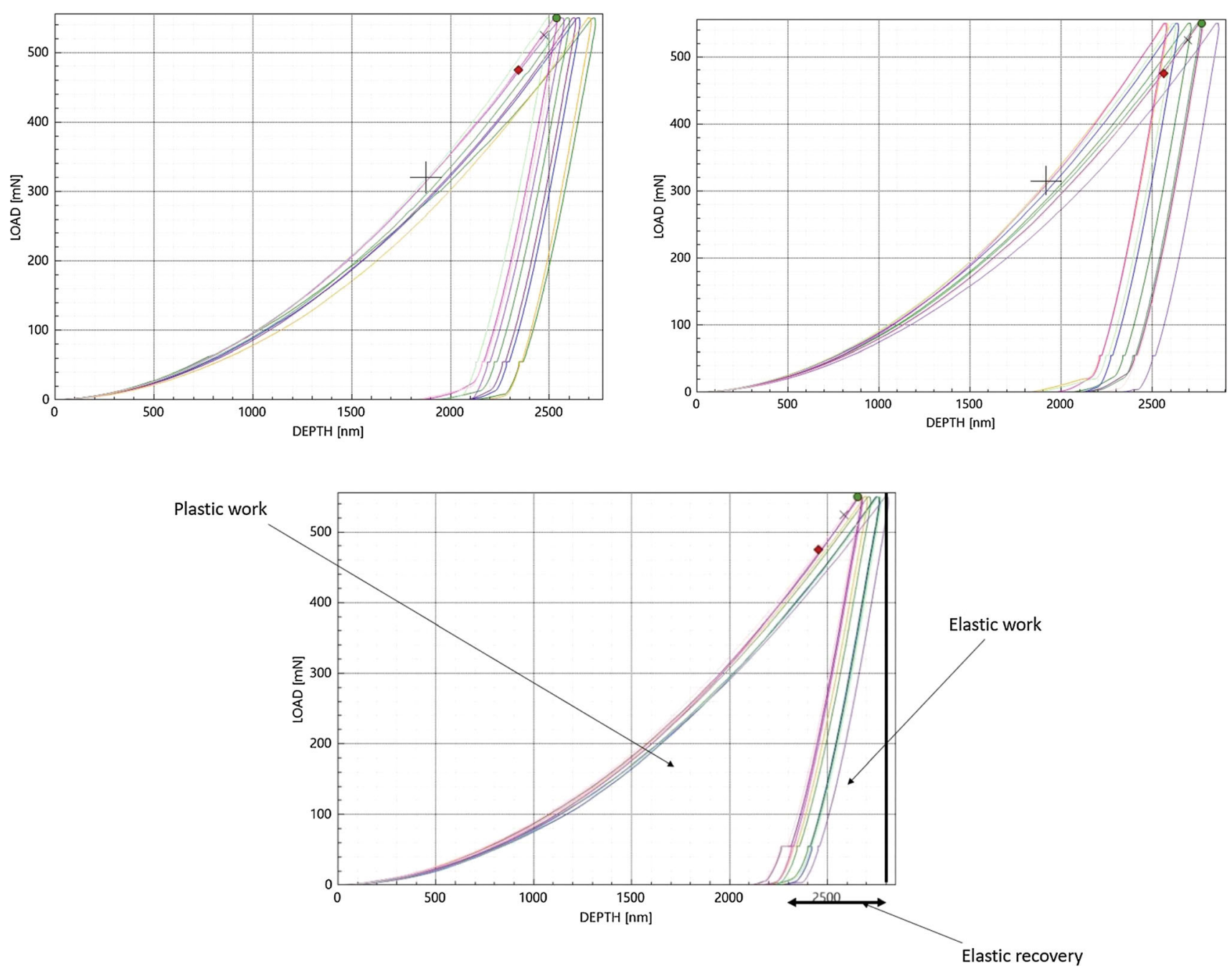

Fig. 7 Nanoindentation load-depth curves for base metal zone, heat affected zone and fusion zone of pulsed-GTAW welded Ti-5Al-2.5Sn alloy in autogenous mode, respectively, at the constant load of $\sim 550 \mathrm{mN}$ and depth of indentation varying from 2500 to $2800 \mathrm{~nm}$ approximately

measured to be approximately $430 \mathrm{MPa}$ closed to the weld centerline (Ref 39).

Values of nanohardness are averaged for the different approaches are shown in Table 2 for comparison. It can be observed that the converted microhardness is lowest for the BM and highest for the FZ, whereas the trend is opposite as observed for the nano hardness measured through different approaches. This is owing to a strong dependence of nanohardness on the state of residual stress. As concluded by Charitidis et al. (Ref 31) a tensile residual stress reduces the nanohardness, whereas according to Jae-il Jang (2009) (Ref 40), the micro hardness is not significantly affected by the state of stress in the material. The increased value of FZ microhardness was observed to be $8.6 \%$ higher than the BM which is owing to the presence of hard phases (acicular $\alpha$ and $\alpha$ ' martensite) formed as a result of fast cooling cycle during solidification of the weldments (Ref 39, 41). However, the tensile state of residual stress in the weld region is expected to be highest in the FZ as calculated in the previous study (Ref 21 ). Since this type of stress profile is characteristic of a weld in which the shrinkage phenomenon is dominant and according to Rossini et al. (2012) (Ref 42) is maximum at the FZ. This resulted in a significant reduction in the FZ nano hardness by approximately $9 \%$ in $\mathrm{OP}$ method, $16 \%$ in AFM analysis, $8 \%$ in Total work approach and plastic work approach as compared to the BM.

The reduced or combined elastic modulus was also calculated using Oliver and Pharr approach and AFM analysis. Kim et al. (Ref 43) calculated the values of elastic moduli for titanium alloys using Ultrasonic Pulse-echo technique by a twochannel digital real-time oscilloscope on TDS220 (Tektronics, Inc., USA). This value of elastic modulus for Ti-5Al-2.4Sn calculated using Ultrasonic Pulse-echo technique is approximately $130 \mathrm{GPa}$ (Ref 43), whereas those calculated through nanoindentation are provided in Table 3. This significant difference also suggests the influence of residual stresses on the nanomechanical properties on which further investigation is required.

Although nanoindentation is an excellent technique for measuring properties in microscale dimensions such as thin film coatings. Numerous studies were undertaken for on ascertaining properties on bulk weldments using nanoindentation. Chariditis et al. studied friction stir welded 10-mm thick AA6082-T6 and AA5083-H111 aluminum alloys using nanoindentation and determined nanohardness, normalized pile up/ sink in and residual stresses (Ref 31). Peng et al. used the nanoindentation load-depth curves and calculated nanohardness 
for 5-mm thick dissimilar FSW aluminum weldments (Ref 44). Similarly, Zhu et al. evaluated the nanohardness of the weld joint in 10-mm thick rotor steel joined by tungsten inert gas

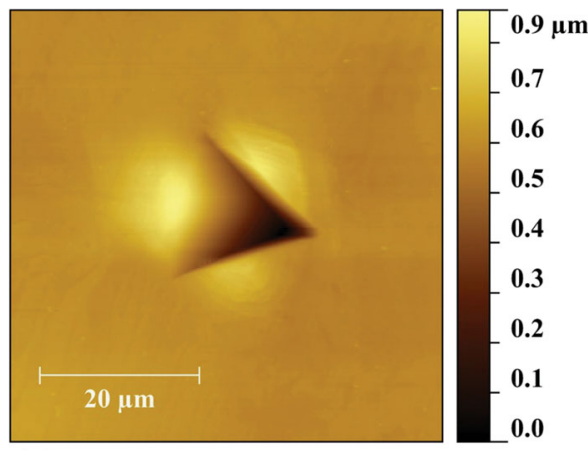

(a)

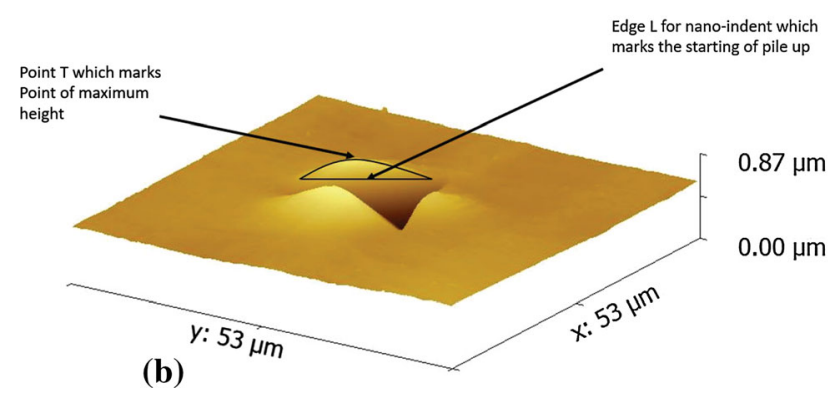

Fig. 8 Three-dimensional AFM image with indentation mark generated on as polished pulsed-GTAW welded Ti-5Al-2.5Sn alloy at $533 \mathrm{mN}$ showing elliptical pile ups for (a) top view, (b) Side view indicating edge $\mathrm{T}$ (marking for the minor axis of the ellipse) and edge $\mathrm{L}$ (marking the major axis for the ellipse)
(TIG) and submerged arc welding (SAW). Nanoindentation technique was employed in this study for localized characterization of $\mathrm{Ti}$ alloy weldment to assess the micrometer scale property distribution along the surface of the weld. As suggested by Ref 45, nanoindentation helps to assess the localized properties of the weldments, especially for steep microstructural gradients across the weld joint. Therefore, properties of each phase present in a zone can be evaluated using nanoindentation, in conjunction with AFM.

\section{Conclusions}

In this work different approaches namely Oliver-Pharr (OP) method, AFM analysis and work of indentation approaches were used to calculate the nanohardness for Ti-5Al-2.5Sn alloys which has been thermo-mechanically processed through pulsed-GTAW in autogenous mode.

- Oliver and Pharr method does not account for the area of pile ups in the correlations and hence overestimates the values of weld nanohardness. Therefore, OP method is giving the highest values for nanohardness compared to the other approaches.

- Weld nanohardness value estimated by AFM analysis was smallest and less than the microhardness value, and therefore, its accuracy is questionable.

- Work of indentation approach measured the nanohardness values which were very close to the microhardness values. Therefore, this method was best suited for Ti-5Al-2.5Sn alloy as it calculated the values almost equal to the microhardness values.

- The results also indicated that the depth of indentation affected the nanohardness values.

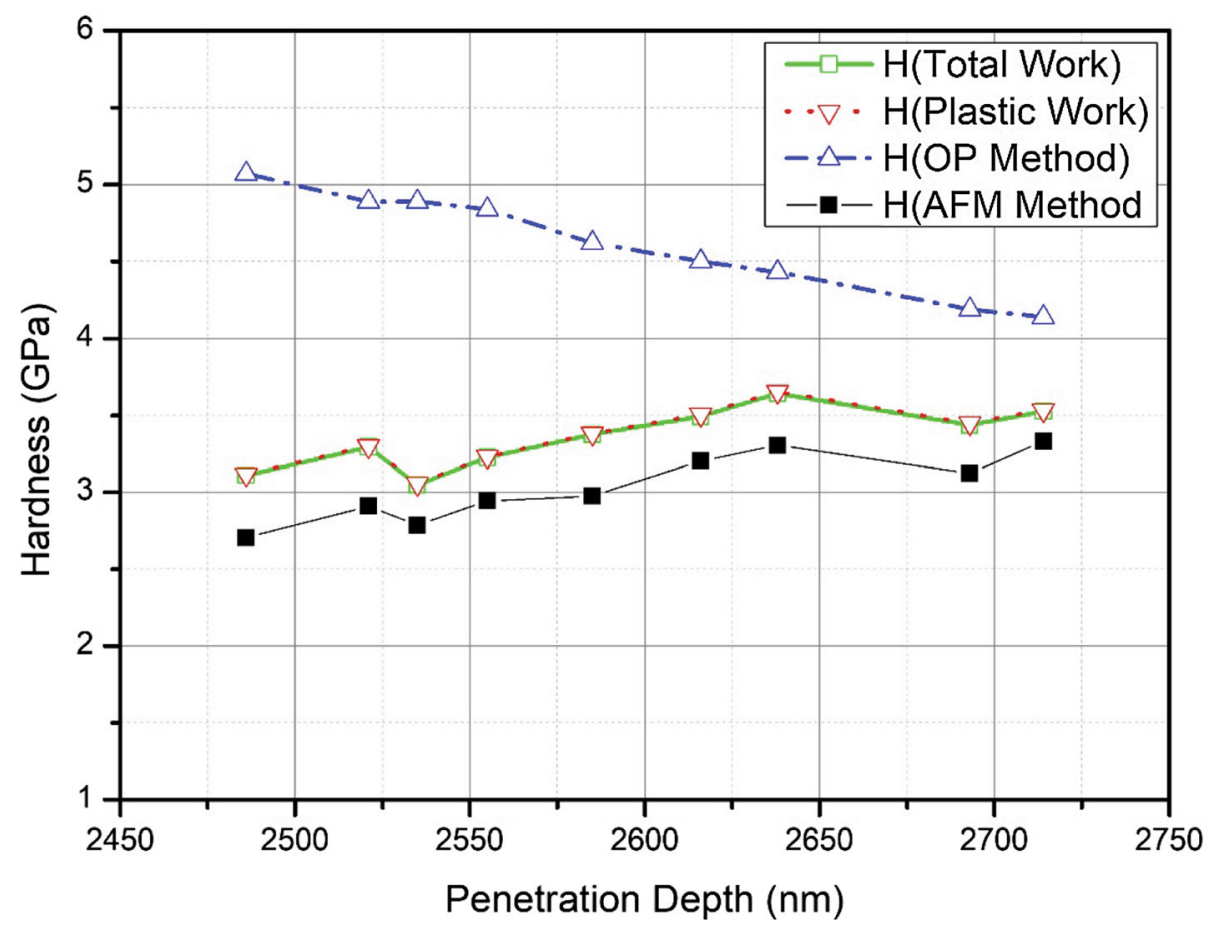

Fig. 9 Nanohardness measured in base metal for pulsed-GTAW welded Ti-5Al-2.5Sn alloy in autogenous mode using (a) Oliver Pharr approach, (b) total work approach, (c) plastic work approach and (d) AFM approach 


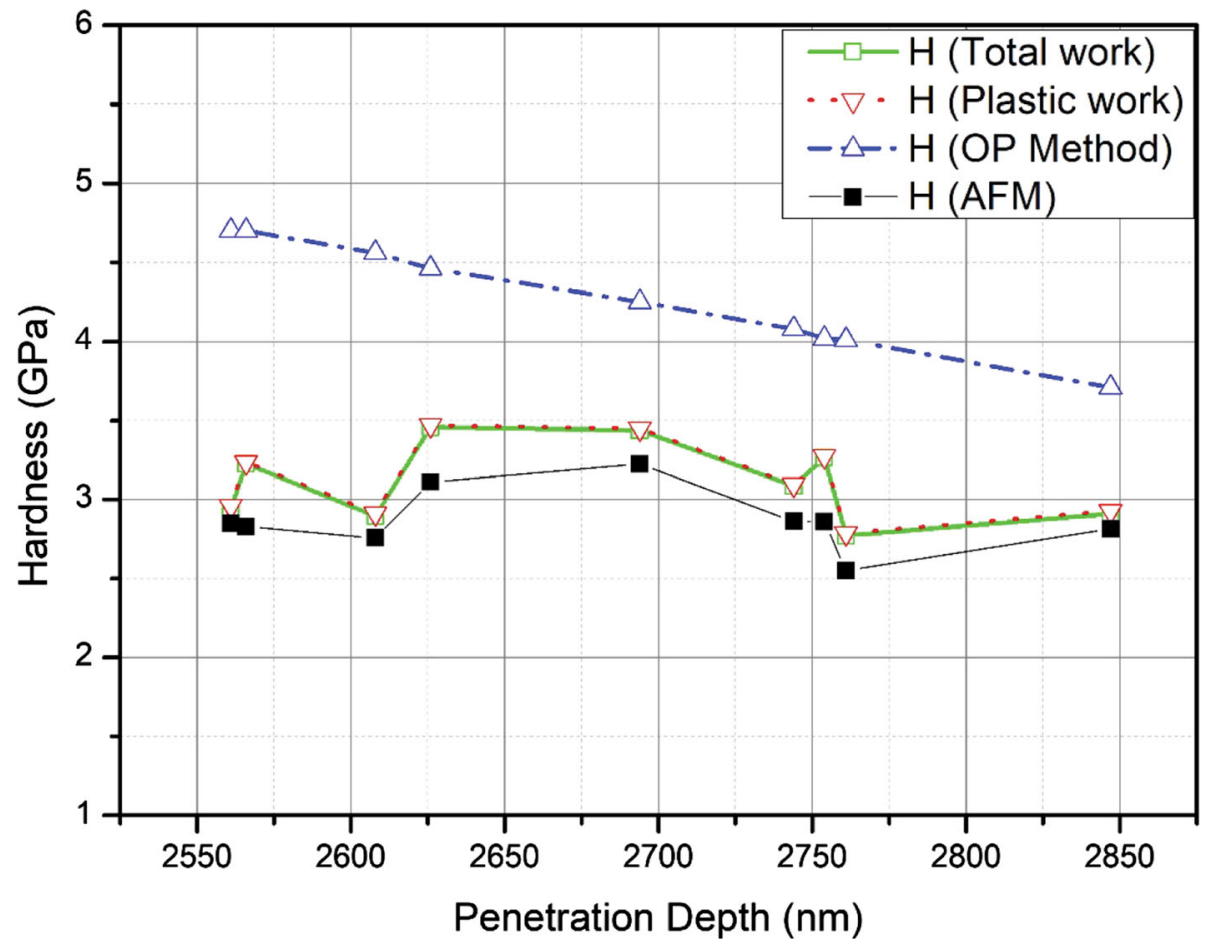

Fig. 10 Nanohardness measured in heat affected zone for pulsed-GTAW welded Ti-5Al-2.5Sn alloy in autogenous mode using (a) Oliver Pharr approach, (b) total work approach, (c) plastic work approach and (d) AFM approach

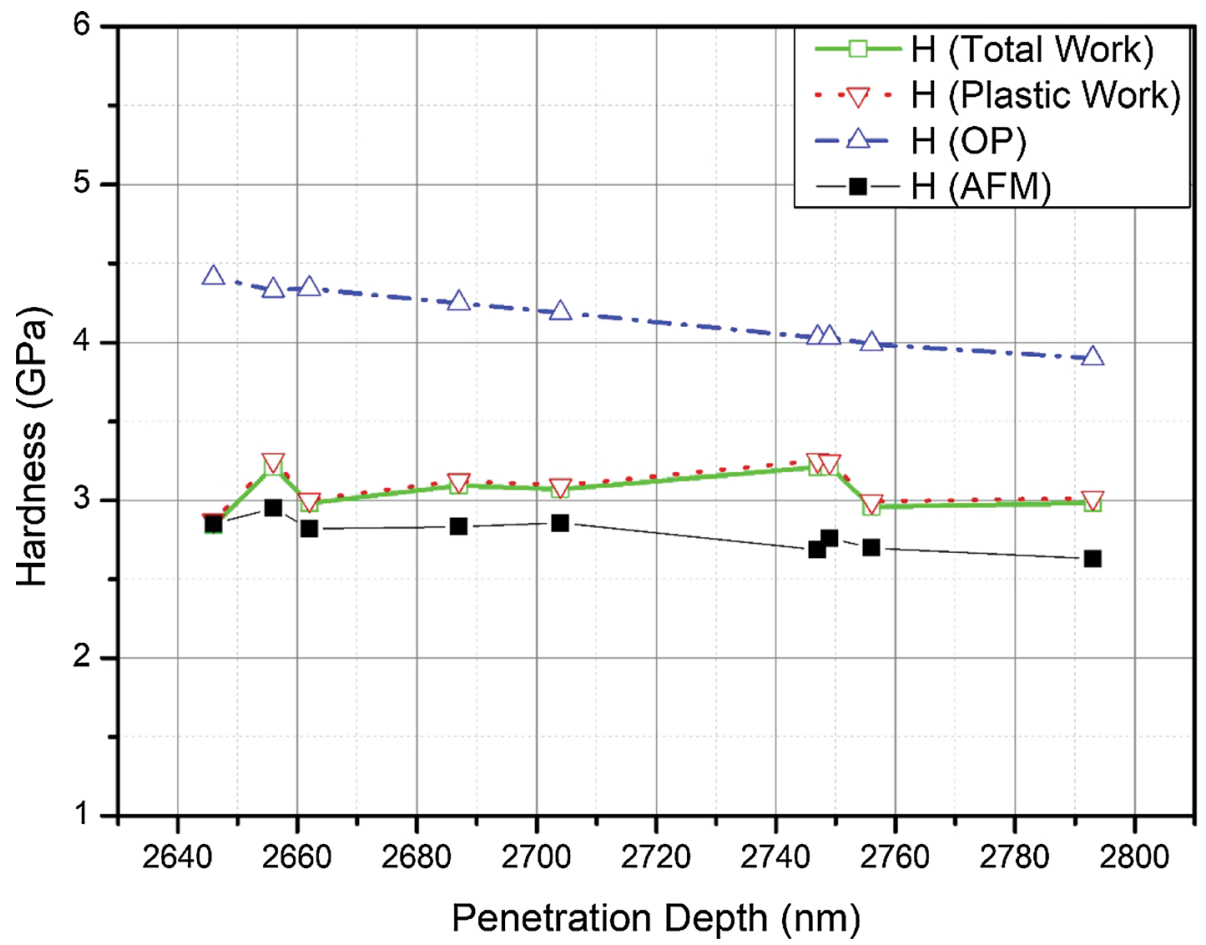

Fig. 11 Nanohardness measured in fusion zone for pulsed-GTAW welded Ti-5Al-2.5Sn alloy in autogenous mode using (a) Oliver Pharr approach, (b) total work approach, (c) plastic work approach and (d) AFM approach 
Table 2 Nanohardness using different approaches for pulsed-GTAW welded Ti-5Al-2.5Sn alloy in autogenous mode in BM, HAZ and FZ

\begin{tabular}{lcccc}
\hline Region & $\begin{array}{c}\text { Oliver and Pharr } \\
\text { hardness, GPa }\end{array}$ & $\begin{array}{c}\text { AFM Analysis } \\
\text { Values, GPa }\end{array}$ & $\begin{array}{c}\text { Total work } \\
\text { hardness, GPa }\end{array}$ & $\begin{array}{c}\text { Plastic work } \\
\text { hardness, GPa }\end{array}$ \\
\hline Base metal & 4.62 & 3.03 & 3.35 & 3.36 \\
$\begin{array}{l}\text { Heat affected } \\
\quad \text { zone }\end{array}$ & 4.28 & 2.87 & 3.11 & 3.12 \\
Fusion zone & 4.16 & 2.80 & 3.06 & 3.09 \\
\hline
\end{tabular}
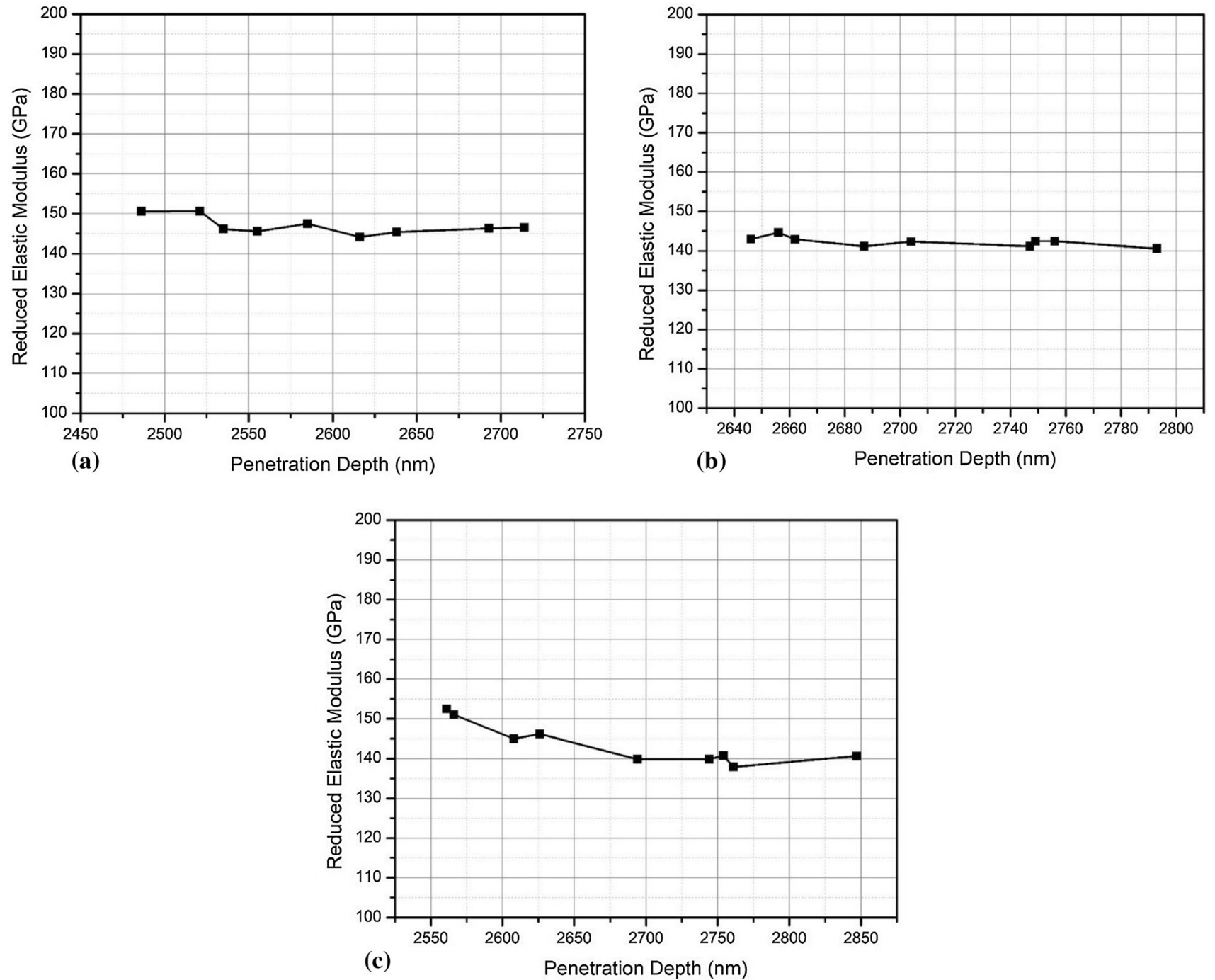

Fig. 12 Effective elastic modulus calculated through nanoindentation for (a) base metal, (b) fusion zone and (c) heat affected zone of pulsedGTAW welded Ti-5Al-2.5Sn alloy in autogenous mode 

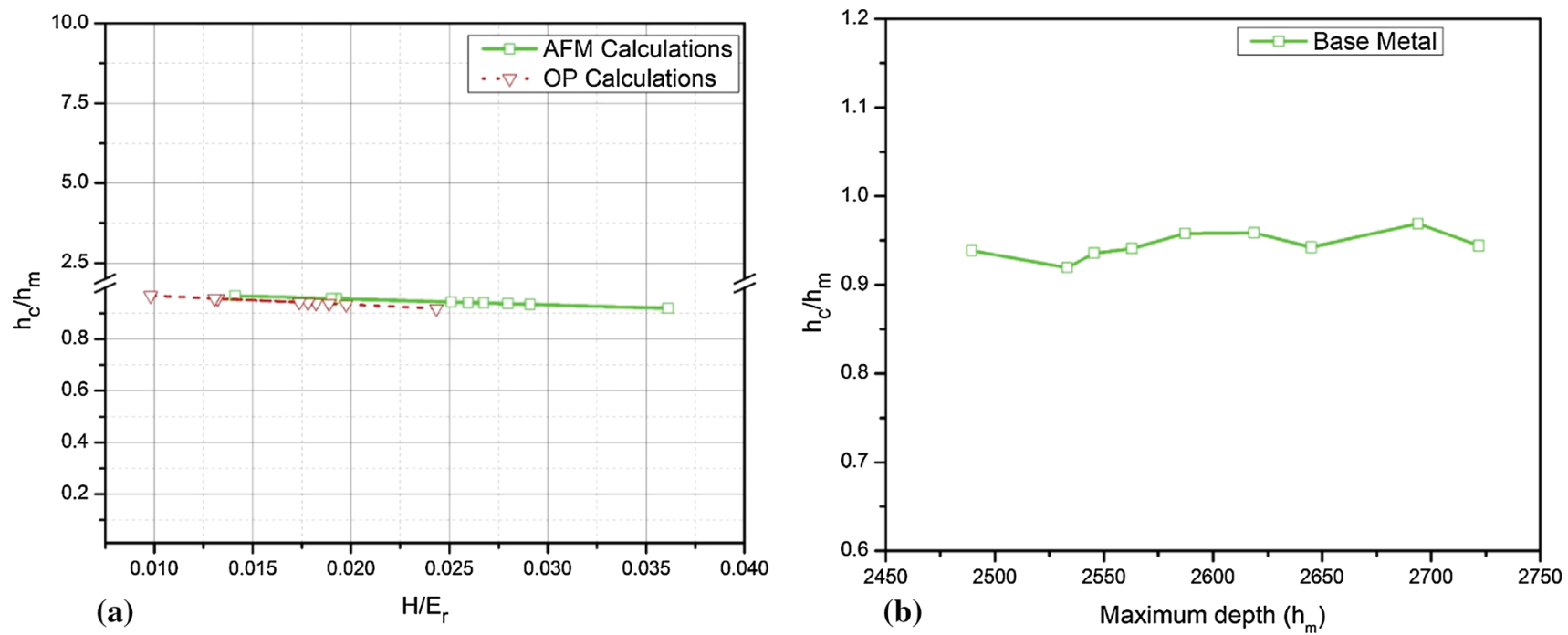

Fig. 13 Pile up/Sink in against (a) normalized hardness and (b) maximum depth for base metal
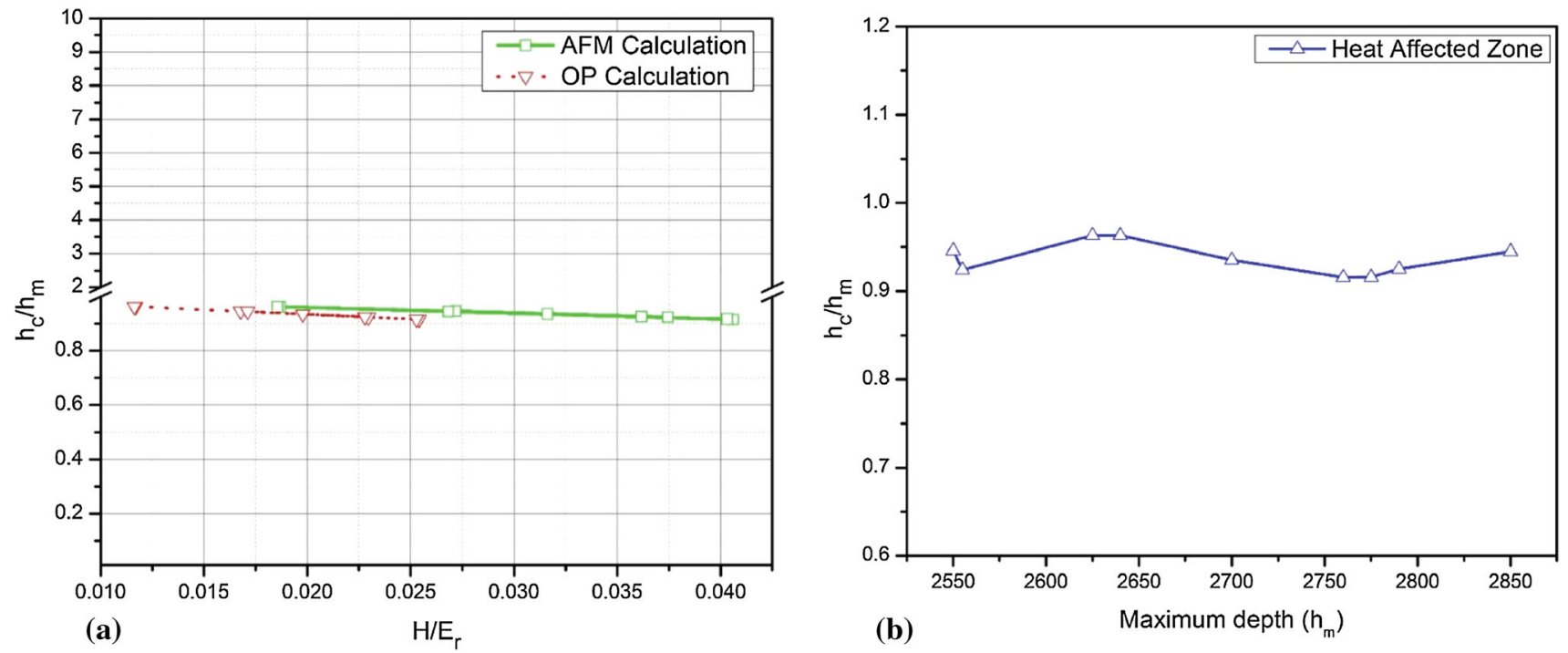

Fig. 14 Pile up/Sink in against (a) normalized hardness and (b) maximum depth for HAZ

- The value of nanohardness showed increasing trend when moving away from the fusion zone to the base metal which was opposite to the trend in microhardness values.
- Furthermore, the nanohardness calculated through plastic work and total work approach were very close to each other. 

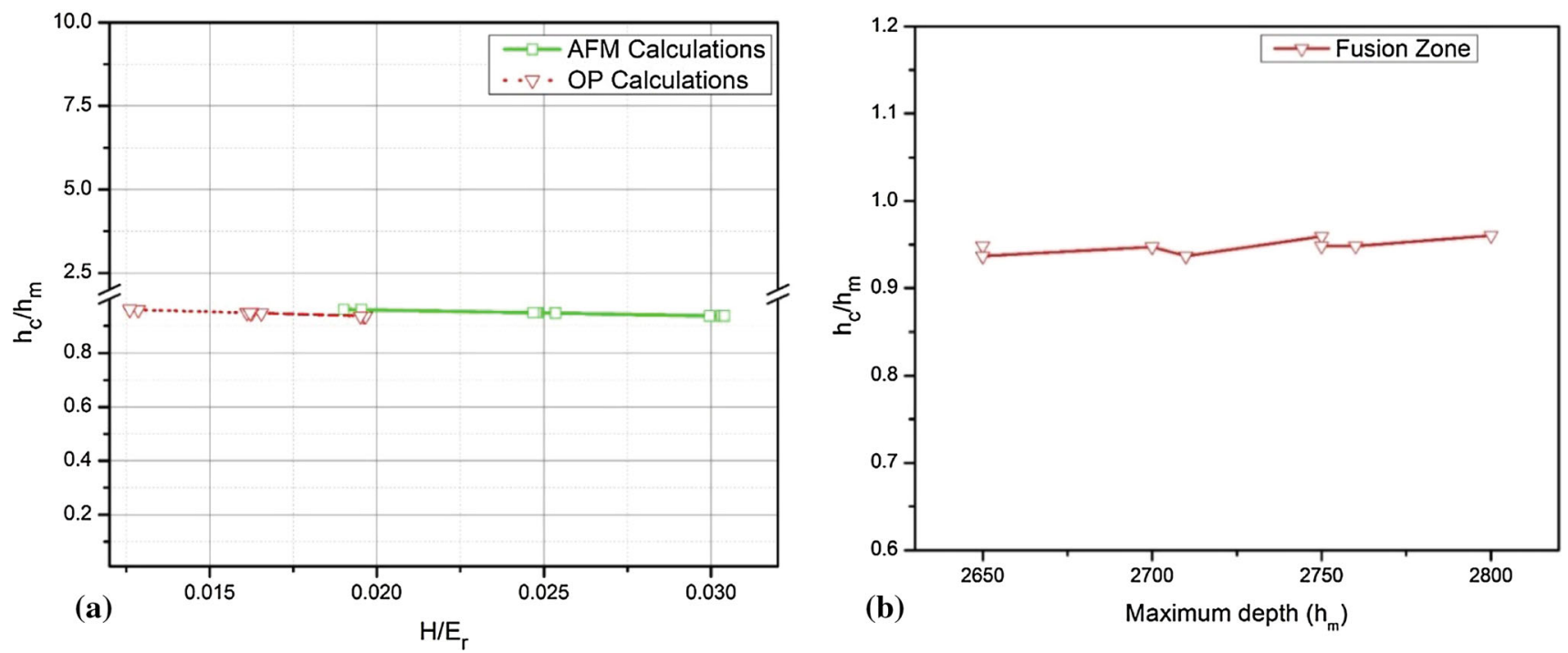

Fig. 15 Values of pile up/sink in against (a) normalized hardness (b) maximum depth for fusion zone

Table 3 Elastic modulus using different approaches for pulsed-GTAW welded Ti-5Al-2.5Sn alloy in autogenous mode in BM, HAZ and FZ

\begin{tabular}{lcc}
\hline Region & $\begin{array}{c}\text { Oliver and Pharr Method, } \\
\text { GPa }\end{array}$ & $\begin{array}{c}\text { AFM values, } \\
\text { GPa }\end{array}$ \\
\hline Base metal & 146.98 & 188.87 \\
$\begin{array}{l}\text { Heat affected } \\
\quad \text { zone }\end{array}$ & 143.75 & 159.75 \\
Fusion zone & 142.28 & 176.21 \\
\hline
\end{tabular}

\section{Open Access}

This article is licensed under a Creative Commons Attribution 4.0 International License, which permits use, sharing, adaptation, distribution and reproduction in any medium or format, as long as you give appropriate credit to the original author(s) and the source, provide a link to the Creative Commons licence, and indicate if changes were made. The images or other third party material in this article are included in the article's Creative Commons licence, unless indicated otherwise in a credit line to the material. If material is not included in the article's Creative Commons licence and your intended use is not permitted by statutory regulation or exceeds the permitted use, you will need to obtain permission directly from the copyright holder. To view a copy of this licence, visit http://creativecommons.org/licenses/by/4.0/.

\section{References}

1. C. Leyens and M. Peters, Titanium and Titanium Alloys: Fundamentals and Applications, Wiley, New York, 2003

2. L.C. Zhang and L.Y. Chen, A Review on Biomedical Titanium Alloys: Recent Progress and Prospect, Adv. Eng. Mater., 2019, 21(4), p 1-29. h ttps://doi.org/10.1002/adem.201801215

3. Z. Chen, B. Wang, and B. Duan, Mechanical Properties and Microstructure of a High-Power Laser-Welded Ti6Al4V Titanium Alloy, J. Mater. Eng. Perform., 1-9, 2020

4. Y.E. Wu and Y.T. Wang, Effect of Filler Metal and Postwelding Heat Treatment on Mechanical Properties of Al-Zn-Mg Alloy Weldments, $J$. Mater. Eng. Perform., 2010, 19(9), p 1362-1369
5. G. Sundararajan and M. Roy, "Hardness Testing," in Encyclopedia of Materials: Science and Technology, 2nd ed., K. H. J. Buschow, R. Cahn, M. Flemings, B. Ilschner, E. Kramer, S. Mahajan, and P. Veyssiere, Eds. Elsevier Ltd., 2001, p 3728-3736

6. S. M. Walley, "Historical Origins of Indentation Hardness Testing Historical Origins of Indentation Hardness Testing, 2013, https://doi. org/10.1179/1743284711y.0000000127

7. H. Buckle, Progress in micro-indentation hardness testing, Metall. Rev, 1959, 4(13)

8. K.E. Puttick and M.M. Hosseini, Fracture by a Pointed Indenter on Near (111) Silicon, J. Phys. D Appl. Phys., 1980, 13(5), p 875-880. h ttps://doi.org/10.1088/0022-3727/13/5/023

9. S.I. Bulychev, V.P. Alekhin, M.H. Shorshorov, A.P. Ternovskii, and G.D. Shnyrev, Determining Young's modulus From the Indentor Penetration Diagram, Ind. Lab., 1975, 41(9), p 1409-1412

10. D.A. Alloys et al., Restorative Materials-Metals, Craig's Restor. Dent. Mater, 2012, https://doi.org/10.1016/b978-0-323-08108-5.1001 $0-6$

11. D. Tabor, Indentation Hardness: Fifty Years on a Personal View, Philos. Mag. A Phys. Condens. Matter. Struct. Defects Mech. Prop., 1996, 74(5), p 1207-1212. https://doi.org/10.1080/01418619608239720

12. Y. Lou, S. Zhang, and J.W. Yoon, A Reduced Yld 2004 Function for Modeling of Anisotropic Plastic Deformation of Metals Under Triaxial Loading, Int. J. Mech. Sci., 2019, 161-162, p 105027. https://doi.org/ 10.1016/j.ijmecsci.2019.105027

13. S.L. Semiatin, N.C. Levkulich, A.A. Salem, and A.L. Pilchak, Plastic Flow During Hot Working of Ti-7Al, Metall. Mater. Trans. A. Phys. Metall. Mater. Sci., 2020, 51(9), p 4695-4710. https://doi.org/10.1007/ s11661-020-05884-0

14. B. Yang and H. Vehoff, Grain Size Effects on the Mechanical Properties of Nanonickel Examined by Nanoindentation, Mater. Sci. Eng.: A, 2005, 401, p 467-470. https://doi.org/10.1016/j.msea.2005. 01.077

15. W.C. Oliver and G.M. Pharr, An Improved Technique for Determining Hardness and Elastic Modulus Using Load and Displacement Sensing Indentation Experiments, J. Mater. Res., 1992, 7(6), p 1564-1583

16. F. Fadaeifard, M.R. Pakmanesh, M.S. Esfahani, K.A. Matori, and D. Chicot, Nanoindentation Analysis of Friction Stir Welded 6061-T6 Al Alloy in As-Weld and Post Weld Heat Treatment, Phys. Met. Metallogr., 2019, 120(5), p 483-491

17. K.O. Kese, Z.C. Li, and B. Bergman, Influence of Residual Stress on Elastic Modulus and Hardness of Soda-Lime Glass Measured by Nanoindentation, J. Mater. Res., 2004, 19(10), p 3109-3119

18. J.R. Tuck, A.M. Korsunskyl, S.J. Bull, and R.I. Davidson, On the application of the Work-of-Indentation Approach to Depth-Sensing Indentation Experiments in Coated Systems, Surf. Coatings Technol., 2001, 137(2-3), p 217-224. https://doi.org/10.1016/S0257-8972(00)0 $1063-\mathrm{X}$ 
19. C. Anthony, Fischer-Cripps, Nanoindentation, Springer, New York, NY, 2011

20. X.-L. Gao, L.-J. Zhang, J. Liu, and J.-X. Zhang, A Comparative Study of Pulsed Nd: YAG Laser Welding and TIG Welding of Thin Ti6Al4V Titanium Alloy Plate, Mater. Sci. Eng., A, 2013, 559, p 14-21

21. M. Junaid and F.N. Khan, Microstructure, Mechanical Properties and Residual Stress Distribution in Pulsed Tungsten Inert Gas Welding, Proc. Inst. Mech. Eng. Pt. L J. Mater. Des. Appl., 2018, 233(10), p 115. https://doi.org/10.1177/1464420718811364

22. D. Smith and C. Nichols, Electrical Properties of Grain Boundaries, Structure and property relationships for interfaces, J. Walter, A. King, and K. Tangri, Ed., ASM International, Cleveland, 1991,

23. F.K. Mante, G.R. Baran, and B. Lucas, Nanoindentation Studies of Titanium Single Crystals, Biomaterials, 1999, 20(11), p 1051-1055. h ttps://doi.org/10.1016/S0142-9612(98)00257-9

24. H. Attar et al., Nanoindentation and Wear Properties of Ti and Ti-TiB Composite Materials Produced by Selective Laser Melting, Mater. Sci. Eng., A, 2017, 688, p 20-26. https://doi.org/10.1016/j.msea.2017.01. 096

25. A. Jamleh et al., Nanoindentation Testing of New and Fractured Nickel-Titanium Endodontic Instruments, Int. Endod. J., 2011, 45(5), p 462-468. https://doi.org/10.1111/j.1365-2591.2011.01997.x

26. W.C. Oliver and G.M. Pharr, Measurement of Hardness and Elastic Modulus by Instrumented Indentation: Advances in Understanding and Refinements to Methodology, J. Mater. Res., 2004, 19(1), p 3-20. h ttps://doi.org/10.1557/jmr.2004.19.1.3

27. J. Dean, G. Aldrich-Smith, and T.W. Clyne, Use of Nanoindentation to Measure Residual Stresses in Surface Layers, Acta Mater., 2011, 59(7), p 2749-2761. https://doi.org/10.1016/j.actamat.2011.01.014

28. Y.M. Huang, Y. Li, K. He, and C.X. Pan, Micrometre Scale Residual Stress Measurement in Fusion Boundary of Dissimilar Steel Welded Joints Using Nanoindenter System, Mater. Sci. Technol., 2011, 27(9), p 1453-1460. https://doi.org/10.1179/026708310X1275 6557336076

29. T.H. Pham, J.J. Kim, and S.E. Kim, Estimation of Microstructural Compositions in the Weld Zone of Structural Steel Using Nanoindentation, J. Constr. Steel Res., 2014, 99, p 121-128. https://doi.org/10. 1016/j.jcsr.2014.04.011

30. M.K. Khan, M.E. Fitzpatrick, S.V. Hainsworth, and L. Edwards, Effect of Residual Stress on the Nanoindentation Response of Aerospace Aluminium Alloys, Comput. Mater. Sci., 2011, 50(10), p 2967-2976. h ttps://doi.org/10.1016/j.commatsci.2011.05.015

31. C.A. Charitidis, D.A. Dragatogiannis, E.P. Koumoulos, and I.A. Kartsonakis, Residual Stress and Deformation Mechanism of Friction Stir Welded Aluminum Alloys by Nanoindentation, Mater. Sci. Eng., A, 2012, 540, p 226-234. https://doi.org/10.1016/j.msea.2012.01.129
32. G. Constantinides and F.J. Ulm, The nanogranular Nature of C-S-H, $J$. Mech. Phys. Solids, Jan. 2007, 55(1), p 64-90. https://doi.org/10.1016/ j.jmps.2006.06.003

33. A. Bolshakov and G.M. Pharr, Influences of pileup on the Measurement of Mechanical Properties by Load and Depth Sensing Indentation Techniques, J. Mater. Res., 1998, 13(4), p 1049-1058

34. R. Saha and W.D. Nix, Soft Films on Hard Substrates-Nanoindentation of Tungsten Films on Sapphire Substrates, Mater. Sci. Eng., A, 2001, 319, p 898-901

35. D. Beegan, S. Chowdhury, and M.T. Laugier, Work of Indentation Methods for Determining Copper Film Hardness, Surf. Coatings Technol., 2005, 192(1), p 57-63

36. R. Hill, B. Storakers, and A.B. Zdunek, Proc. R. Soc. London A, 1989, 423, p 301

37. S. Biwa and B. Storåkers, An Analysis of Fully Plastic Brinell Indentation, J. Mech. Phys. Solids, 1995, 43(8), p 1303-1333

38. H. Hertz, "Miscellaneous papers by H. Hertz," Transl. ed. by D.E. Jones, G.A. Schott, MacMillan Co. Ltd., London, pp. 146-183, 1896

39. M. Junaid, M.N. Baig, M. Shamir, F.N. Khan, K. Rehman, and J. Haider, A comparative Study of Pulsed Laser and Pulsed TIG Welding of Ti-5Al-2.5Sn Titanium Alloy Sheet, J. Mater. Process. Technol., 2017, https://doi.org/10.1016/j.jmatprotec.2016.11.018

40. J. Jang, Estimation of Residual Stress by Instrumented Indentation: A Review Early Studies Using a Conventional, Acta Mater., 2009, 10(3), p 391-400

41. T. Ahmed and H.J. Rack, Phase Transformations During Cooling in $\alpha+\beta$ Titanium Alloys Mater. Sci. Eng., A, 1998, 243(1), p 206-211. h ttps://doi.org/10.1016/S0921-5093(97)00802-2

42. N.S. Rossini, M. Dassisti, K.Y. Benyounis, and A.G. Olabi, Methods of Measuring Residual Stresses in Components, Mater. Des., 2012, 35, p 572-588. https://doi.org/10.1016/j.matdes.2011.08.022

43. K.-H. Kim, Y.-C. Kim, E. Jeon, and D. Kwon, Evaluation of Indentation Tensile Properties of Ti Alloys by Considering Plastic Constraint Effect, Mater. Sci. Eng., A, 2011, 528(15), p 5259-5263

44. G. Peng et al., Nanoindentation Hardness Distribution and Strain Field and Fracture Evolution in Dissimilar Friction Stir-Welded AA 6061AA 5A06 Aluminum Alloy Joints, Adv. Mater. Sci. Eng., 2018, 2018, p 11. https://doi.org/10.1155/2018/4873571

45. J.M. Vitek and S.S. Babu, Multiscale Characterisation of Weldments, Sci. Technol. Weld. Join., 2011, 16(1), p 3-12. https://doi.org/10.1179/ 1362171810Y.0000000003

Publisher's Note Springer Nature remains neutral with regard to jurisdictional claims in published maps and institutional affiliations. 